\title{
Perioperative complications and oncological outcomes following radical cystectomy among different racial groups: A long-term, single-center study
}

\author{
Alireza Ghoreifi, MD; Anirban P. Mitra, MD; Jie Cai, MD; Gus Miranda, BS; Siamak \\ Daneshmand, MD; Hooman Djaladat, MD, MS \\ Institute of Urology, Norris Comprehensive Cancer Center, University of Southern California, Los Angeles, CA, \\ United States
}

Cite as: Can Urol Assoc J 2020 May 12; Epub ahead of print. http://dx.doi.org/10.5489/cuaj.6293

Published online May 12, 2020

$* * *$

\section{Abstract}

Introduction: Current literature on perioperative and oncological outcomes following radical cystectomy among different racial groups is limited, especially among Hispanics and Asians. The objective of this study was to assess the impact of racial differences on perioperative and oncological outcomes in a large cohort of bladder cancer patients who underwent radical cystectomy.

Methods: We retrospectively reviewed the records of 3293 patients who underwent radical cystectomy with curative intent at our institution between 1971 and 2017. Based on race, patients were categorized as Hispanic ( $\mathrm{n}=190)$, Asian $(\mathrm{n}=145)$, African Americans $(\mathrm{n}=67)$, and Caucasian $(\mathrm{n}=2891)$. Baseline characteristics, pericystectomy complications, and oncological outcomes, including recurrence-free and overall survival, were compared between the racial groups. Results: Mean patient age was $68 \pm 10.6$ years. Median followup was 10.28 years. Body masss index and American Society of Anesthesiologists scores were significantly higher in Hispanic and African American population, and smoking incidence was lower in Asian patients. Hispanics presented with significantly higher clinical stage and longer time interval from diagnosis to treatment (mean 85.5 vs. 75.4 days in Caucasians, $\mathrm{p}<0.001$ ). Overall 90 -day complication and readmission rates were higher in Hispanics (41.06\% and 18.95\%, respectively). Oncological outcomes, however, were comparable between different race groups. In multivariate analysis, pathological nodal status and lymphovascular invasion were independent predictors of oncological outcomes, but race was not.

Conclusions: In this very large, ethnically diverse patient cohort who underwent radical cystectomy with curative intent, pericystectomy complications were more common in Hispanics; however, race was not an independent predictor of long-term oncological outcome. 


\section{Introduction}

Radical cystectomy ( $\mathrm{RC}$ ) with urinary diversion is a complex urologic procedure involving surgery on the genitourinary and gastrointestinal systems. This is associated with significant morbidity as well as intra and postoperative complications. ${ }^{1}$ The optimal goals of RC include prevention of recurrence or metastasis, improved survival and a minimizing the decrease in quality of life. Long-term outcomes following major surgical oncologic procedures has improved significantly over the last two decades; however, almost half of all patients still experience disease recurrence within 5 years following radical cysstectomy. ${ }^{2,3}$ Furthermore, these improvements are not consistent across all population and racial groups. ${ }^{2}$ While distinctions in disease pathophysiology may explain some of these differences, variability in non-biological (i.e. social, economic and environmental) factors may also contribute to these findings. ${ }^{4} \mathrm{Few}$ data exist on the perioperative and oncological outcomes of $\mathrm{RC}$ in different racial groups. Among the available data, most studies include the African Americans (AAs) and Caucasians, and there is limited representation of Hispanic and Asian patients. ${ }^{5}$ The objective of this study was to assess the impact of racial differences on perioperative and oncological outcomes in a large cohort of bladder cancer patients who underwent RC in a single institution.

\section{Methods}

\section{Patients and followup}

Using our institutional review board-approved bladder cancer database, we retrospectively reviewed records of patients who underwent $\mathrm{RC}$ with curative intent at our institution between 1971 and 2017. Patients with missing data of interest and those who underwent salvage cystectomy after radiation therapy were excluded from enrollment. The final cohort consisted of 3293 patients. Based on race, patients were divided into four groups: Caucasians, Hispanics, Asian Americans and AAs. Baseline demographic and clinical characteristics including age, sex, body mass index (BMI), smoking status, American Society of Anesthesiologists (ASA) score, Charlson Comorbidity Index (CCI), time from diagnosis to treatment, neoadjuvant chemotherapy (NAC) status, clinical stage and type of diversion were compared between racial groups. Pathologic features including pathologic stage, presence of carcinoma in situ, lymphovascular invasion (LVI), positive margins and associated variant histology were also compared among the racial groups. Following surgery, patients were followed every 4 months in the first year, every 6 months up to 5 years and annually thereafter. Follow-up included physical examination, serum chemistry studies, and radiographic surveillance. The majority of patients were contacted prospectively throughout the 90-day postoperative period to inquire about recent complications or symptoms and records for follow-up or complications managed outside our institution were regularly obtained. To investigate the impact of racial variations on perioperative complications and oncological outcomes following RC, we compared 90-day complications and readmissions, recurrence status, overall survival (OS) and 3-year recurrence free survival (RFS) across the 
racial groups. OS was defined as the time from surgery to death (any cause). In the absence of an event, RFS and OS were censored at last follow-up.

\section{Data analysis}

Independent characteristics were compared between the study groups using frequency tables and Pearson's Chi-square or Fisher's exact test for categorical variables and analyses of variance for continuous variables. When variables were not normally distributed, Wilcoxon rank sum test was used to assess differences. Kaplan-Meier plots were used to estimate the probabilities of OS and RFS. Cox proportional hazard models, through stepwise selection, were utilized to identify independent prognostic factors for oncologic outcomes in multivariable setting. SAS, Version 9.3 (SAS Institute Inc., Cary, NC, USA) was used for all the analyses. All p values reported are two-sided and $\mathrm{p}<0.05$ was considered statistically significant.

\section{Results}

A total of 3293 patients with a mean age of $68 \pm 10.6$ years and median follow-up period of 10.28 (range 0.1-40.43) years were included in the analysis. Patient characteristics and clinical/pathologic features are shown in Table 1. BMI and ASA score were significantly higher in Hispanic and AA patients ( $<<0.001, p=0.003$, respectively). Smoking incidence was lower in Asian patients $(\mathrm{p}<0.001)$. Hispanics presented with significantly higher clinical stage and longer time interval from diagnosis to treatment $(85.5$ versus 75.4 days in Caucasians, $p<0.001)$.

Perioperative complications and oncologic outcomes of the patients are shown in Table 2. 90-day complication and readmission rates were significantly higher in Hispanics $(41.06 \%$, $\mathrm{p}<0.001 ; 18.95 \%, \mathrm{p}=0.001$, respectively). However, oncologic outcomes including recurrence rate, 3 and 5-year OS, and 3-year RFS were comparable between different racial groups.

In multivariate analysis, age $>65, \mathrm{CCI} \geq 1$, positive lymph nodes, LVI, heterotopic urinary diversion, neo-adjuvant and adjuvant chemotherapy were independent predictors of survival. Furthermore, positive lymph nodes, LVI, heterotopic urinary diversion and neoadjuvant chemotherapy were independent predictors of recurrence, but race was not (Table 3 ).

\section{Discussion}

Among available data on outcomes of bladder cancer among racial groups, most studies include AAs and Caucasians, yet few data is available for Hispanic and Asian patients. Prior publications have suggested that minorities undergoing both oncologic and non-oncologic surgeries may have higher postoperative complication rates compared to their Caucasian counterparts. ${ }^{6-8}$ Access to healthcare and the quality of care delivery to minority populations may potentially contribute to this difference. However, few conflicting data exist on urologic surgeries including RC. Using the Healthcare Cost and Utilization Project State Inpatient Databases, Barocas et al demonstrated that regardless of payer type, AAs had worse perioperative outcomes even for those who received care at high-volume centers. ${ }^{9}$ On the other hand, a study of patients from Nationwide 
Inpatient Sample database showed that AAs undergoing major surgical oncological procedures were more likely to experience postoperative complications (specifically vascular, wound, gastrointestinal and infectious), in-hospital mortality, homologous blood transfusions and prolonged hospital stay. However, AA and Hispanic patients undergoing RC experienced no disparities relative to Caucasian patients in terms of in-hospital mortality or overall postoperative complications. ${ }^{10}$ There are two other studies based on the American College of Surgeons National Surgical Quality Improvement Program database that were specifically designed to characterize postoperative complications. The first study demonstrated that AAs had greater odds of experiencing prolonged length of stay after 10 of the 16 urologic procedures studied including RC. Although AAs had greater odds of postoperative renal complications and Hispanics had a greater odds of blood transfusion compared to Caucasians, both groups showed no difference in overall complications after RC. Interestingly, there was no disparity across Caucasian, AA, and Hispanic patients in odds of 30-day mortality after any surgery. ${ }^{11}$ The second study found no significant differences in complication rates between AA and Caucasian patients for any Clavien grade after RC. Furthermore, after controlling for a higher comorbidity burden among AA patients, AA race was again not independently associated with 30-day postoperative complications for RC. ${ }^{12}$ The results of these studies showed that although AA patients were more likely to experience postoperative complications after different urologic and non-urologic surgeries, there is no difference between AAs and Hispanics compared to Caucasians in terms of early complications and mortality after RC. However, there is no available data on Asian patients. Our study showed that 90 -day perioperative complications and readmission rates were higher in minorities compared to Caucasians. Hispanics had the highest 90-day postoperative complication rate followed by Asians. The transfusion rate was also higher in minorities compared to Caucasians. Among complication subgroups, only bleeding was significantly higher in Hispanic patients. It is noteworthy that the reported postoperative complications are mostly belonging to pre enhanced recovery after surgery (ERAS) era in our institusion and are captured retrospectively. Finally, 90-day mortality rate was the same between the 4 racial groups.

Studies describing racial differences in oncological outcomes following RC show conflicting results. Many of these studies are conducted based on the Surveillance, Epidemiology, and End Results Program database that mainly relies on insurance claims data. ${ }^{13-}$ ${ }^{19}$ Older studies on this database showed that AA race was an independent predictor of poor survival, adjusting for different variables (i.e. age, marital status, region of the country, stage, grade, treatment received, and interaction between race and region). ${ }^{19}$ Furthermore, 5 -year disease-specific survival was consistently worse for AAs than for other racial groups, even when stratified by stage and grade. It was reported as $82.8 \%$ in Caucasians compared with $70.2 \%$ in AAs, $80.7 \%$ in Hispanics and $81.9 \%$ in Asian/Pacific Islanders. ${ }^{15}$ Interestingly, a recent study on the same database showed that bladder-cancer specific mortality is not higher in AAs compared to Caucasians. Kaye et al based on the analysis of patients between 1973 and 2011 stated that 
although AAs had worse all-cause and cancer-specific mortality by univariable analysis, after accounting for sex, age, year of diagnosis, marital status, region of treatment, and stage at cystectomy, all-cause mortality was significant (HR 1.2), but not bladder-cancer specific mortality. ${ }^{14}$ The studies on other databases also showed this controversy. Studies on the Florida Cancer Data System, the Agency for Health Care Administration data sets and US National Cancer Database demonstrated that AA race was statistically significantly and independently associated with poor outcome and OS compared to Caucasians. ${ }^{20-22}$ On the other hand, Schinkel et al showed that although AA patients were more likely to present with muscle invasive bladder cancer than Caucasians, no significant racial differences in OS (HR 0.96) or RFS (HR 0.94) were observed after adjustment for demographic variables, tumor characteristics and treatment. ${ }^{23}$ Manoharan et al showed that Hispanic patients present with higher disease stage; however, disease-free and cancer-specific survivals as well as OS are not significantly different compared to non-Hispanic white patients. ${ }^{24}$ Similarly, Hispanics in our study presented with significantly higher clinical stage and longer time interval from diagnosis to treatment. However, the pathologic features were comparable between different racial groups. Interestingly, oncologic outcomes were also comparable between four different racial groups.

One may hypothesize that tumor biology and genetic factors can partly account for the observed racial differences in bladder cancer oncological outcomes. However, non-genetic factors, such as health systems, healthcare providers and unequal access to care may likely also contribute to health disparities. ${ }^{4}$ Nearly $50 \%$ of AAs are either uninsured or use other public insurance which is about two-fold more than Caucasians. ${ }^{26}$ AAs receive a greater proportion of their care at low-volume hospitals which can affect their survival rates. ${ }^{27}$ Furthermore, they are less likely to receive cystectomy by high volume surgeons and undergo evidence-based care (i.e. standard PLND and continent diversion) and more likely to have partial rather than RC. ${ }^{9}$ There is some evidence that patients suffering from both urologic and non-genitourinary malignancies with equivalent access to care and treatment have similar outcomes, regardless of race or ethnicity. ${ }^{28-30}$ For instance, race/ethnicity was not a preoperative risk factor for mortality or prolonged hospital length of stay after cystectomy among patients treated at Veterans Affairs Medical Centers nationwide. ${ }^{30}$ Based on the available data, the effect of race on oncological outcome following $\mathrm{RC}$ is yet to be proven and multi-institutional studies on large cohorts are needed to show the specified relationship.

In our study, the varibales were adjusted for different confounding factors including time intervals by decades. Based on the multivariable analysis, the negative independent predictors of both survival and recurrence were positive lymph nodes, LVI, heterotopic urinary diversion and NAC. This is in contrast to the randomized trials which showed significat increase in survival with neoadjuvant therapy. ${ }^{25}$ The reason for that is most of the patients who received NAC in our cohort were those with high stage (i.e. T3/T4 and/or bulky lymph nodes) disease. This selection bias may affect the results. 
An important limitation of our study was its retrospective nature and the relatively small percentage of AA patients available for analysis. Furthermore, results of this study may be associated with referral bias as most of our patients were insured and presumably from higher socioeconomic status. However, this potentially also highlights the fact that racial disparities seen in most other studies could be a consequence of socioeconomic inequalities. In addition, this study represents one of the largest cohorts of Caucasian, Hispanic and Asian patients who underwent standardized surgery by expert urologic oncologists with curative intent. Furthermore, all the specimens were reviewed by expert GU pathologists.

\section{Conclusions}

In this very large, ethnically diverse long-term follow-up study of RC with curative intent, perioperative complications were more common in Hispanics. Furthermore, this racial group presented with significantly higher clinical stage and longer time interval from diagnosis to treatment. Presence of positive lymph nodes, LVI, heterotopic urinary diversion and neoadjuvant chemotherapy were independent predictors of long-term oncologic outcome (OS and RFS), but race was not. 


\section{References}

1. Liedberg F. Early complications and morbidity of radical cystectomy. Eur Urol Suppl 2010; 9(1):25-30. https://doi.org/10.1016/j.eursup.2010.01.007

2. Sun M, Karakiewicz PI, Sammon JD, et al. Disparities in selective referral for cancer surgeries: implications for the current healthcare delivery system. BMJ open 2014; 4(3):e003921. http://dx.doi.org/10.1136/bmjopen-2013-003921

3. Stein JP, Lieskovsky G, Cote R, et al. Radical cystectomy in the treatment of invasive bladder cancer: long-term results in 1,054 patients. J Clin Oncol 2001; 19(3):666-675. https://doi.org/10.1200/JCO.2001.19.3.666

4. Jacobs BL, Montgomery JS, Zhang Y, et al. Disparities in bladder cancer. Urol Oncol 2012; 30(1):81-8. https://doi.org/10.1016/j.urolonc.2011.08.011

5. Bhanvadia SK. Bladder Cancer Survivorship. Curr Urol Rep 2018; 19(12):111. https://doi.org/10.1007/s11934-018-0860-6

6. Dixit N, Crawford GB, Lemonde M, et al. Left behind: cancer disparities in the developed world. Support Care Cancer 2016; 24(8):3261-3264. https://doi.org/10.1007/s00520-016-3192-4

7. Schoenfeld AJ, Tipirneni R, Nelson JH, et al. The influence of race and ethnicity on complications and mortality after orthopedic surgery: a systematic review of the literature. Med Care 2014; 52(9):842-851. https://doi.org/10.1097/MLR.0000000000000177

8. Nathan H, Frederick W, Choti MA, et al. Racial disparity in surgical mortality after major hepatectomy. J Am Coll Surg 2008; 207(3):312-319. https://doi.org/10.1016/j.jamcollsurg.2008.04.015

9. Barocas DA, Alvarez J, Koyama T, et al. Racial variation in the quality of surgical care for bladder cancer. Cancer 2014; 120(7):1018-1025. https://doi.org/10.1002/cncr.28520

10. Sukumar S, Ravi P, Sood A, et al. Racial disparities in operative outcomes after major cancer surgery in the United States. World J Surg 2015; 39(3):634-643. https://doi.org/ doi: 10.1007/s00268-014-2863-x.

11. Ravi P, Sood A, Schmid M, et al. Racial/Ethnic Disparities in Perioperative Outcomes of Major Procedures: : Results From the National Surgical Quality Improvement Program. Ann Surg 2015; 262(6):955-964. https://doi.org/

12. Parker DC, Handorf E, Smaldone MC, et al. Race and postoperative complications following urologic cancer surgery: An ACS-NSQIP analysis. Urol Oncol 2017; 35(12):670.e1-670.e6. https://doi.org/10.1016/j.urolonc.2017.08.001

13. Wang Y, Chang Q, Li Y. Racial differences in Urinary Bladder Cancer in the United States. Sci Rep 2018; 8(1):12521. https://doi.org/10.1038/s41598-018-29987-2.

14. Kaye DR, Canner JK, Kates M, et al. Do African American patients treated with radical cystectomy for bladder cancer have worse overall survival? Accounting for pathologic staging and patient demographics beyond race makes a difference. Bladder Cancer 2016; 2(2):225-234. https://doi.org/ 10.3233/BLC-150041

15. Yee DS, Ishill NM, Lowrance WT, et al. Ethnic differences in bladder cancer survival. Urology 2011; 78(3):544-549. https://doi.org/10.1016/j.urology.2011.02.042 
16. Hollenbeck BK, Dunn RL, Ye Z, et al. Racial differences in treatment and outcomes among patients with early stage bladder cancer. Cancer 2010; 116(1):50-56. https://doi.org/10.1002/cncr.24701

17. Scosyrev E, Noyes K, Feng C, et al. Sex and racial differences in bladder cancer presentation and mortality in the US. Cancer 2009; 115(1):68-74. https://doi.org/10.1002/cncr.23986

18. Lee CT, Dunn RL, Williams C, et al. Racial disparity in bladder cancer: trends in tumor presentation at diagnosis. J Urol 2006; 176(3):927-934. https://doi.org/10.1016/j.juro.2006.04.074

19. Underwood III W, Dunn RL, Williams C, et al. Gender and geographic influence on the racial disparity in bladder cancer mortality in the US. J Am Coll Surg 2006; 202(2):284290. https://doi.org/10.1016/j.jamcollsurg.2005.09.009

20. Brookfield KF, Cheung MC, Gomez C, et al. Survival disparities among African American women with invasive bladder cancer in Florida. Cancer 2009; 115(18):41964209. https://doi.org/10.1002/cncr.24497

21. Dizman N, Pal SK, Nelson RA, et al. Impact of race on survival following radical cystectomy for muscle-invasive bladder cancer (MIBC): Analysis of the US National Cancer Database (NCDB). Ann Oncol 2016; 27(suppl_6): 794P. https://doi.org/10.1093/annonc/mdw373.22

22. Schinkel JK, Shao S, Zahm SH, et al. Overall and recurrence-free survival among black and white bladder cancer patients in an equal-access health system. Cancer Epidemiol 2016; 42:154-158. https://doi.org/10.1016/j.canep.2016.04.012

23. Gild P, Wankowicz SA, Sood A, et al. Racial disparity in quality of care and overall survival among black vs. white patients with muscle-invasive bladder cancer treated with radical cystectomy: A national cancer database analysis. Urol Oncol 2018; 36(10):469.e1-469.e11. https://doi.org/10.1016/j.urolonc.2018.07.012

24. Manoharan M, Ayyathurai R, Santos R, et al. Presentation and outcome following radical cystectomy in Hispanics with bladder cancer. Int Braz J Urol 2008; 34(6):691-698. http://dx.doi.org/10.1590/S1677-55382008000600003

25. Witjes JA, Lebret T, Compérat EM, et al. Updated 2016 EAU guidelines on muscleinvasive and metastatic bladder cancer. Eur Urol 2017; 71(3):462-75. https://doi.org/10.1016/j.eururo.2016.06.020

26. Ward E, Halpern M, Schrag N, et al. Association of insurance with cancer care utilization and outcomes. CA Cancer J Clin 2008; 58(1):9-31. https://doi.org/10.3322/CA.2007.0011

27. Liu JH, Zingmond DS, McGory ML, et al. Disparities in the utilization of high-volume hospitals for complex surgery. JAMA 2006; 296:1973-1980. https://doi.org/10.1001/jama.296.16.1973

28. McCollum AD, Catalano PJ, Haller DG, et al. Outcomes and toxicity in African American and Caucasian patients in a randomized adjuvant chemotherapy trial for colon cancer. J Natl Cancer Inst 2002; 94:1160-1167. https://doi.org/10.1093/jnci/94.15.1160

29. Dignam JJ. Differences in breast cancer prognosis among African-American and Caucasian women. CA Cancer J Clin 2000; 50(1):50-64.

https://doi.org/10.3322/canjclin.50.1.50 
30. Hollenbeck BK, Miller DC, Taub DA, et al. The effects of adjusting for case mix on mortality and length of stay following radical cystectomy. J Urol 2006; 176:1363-1368. https://doi.org/10.1016/j.juro.2006.06.015

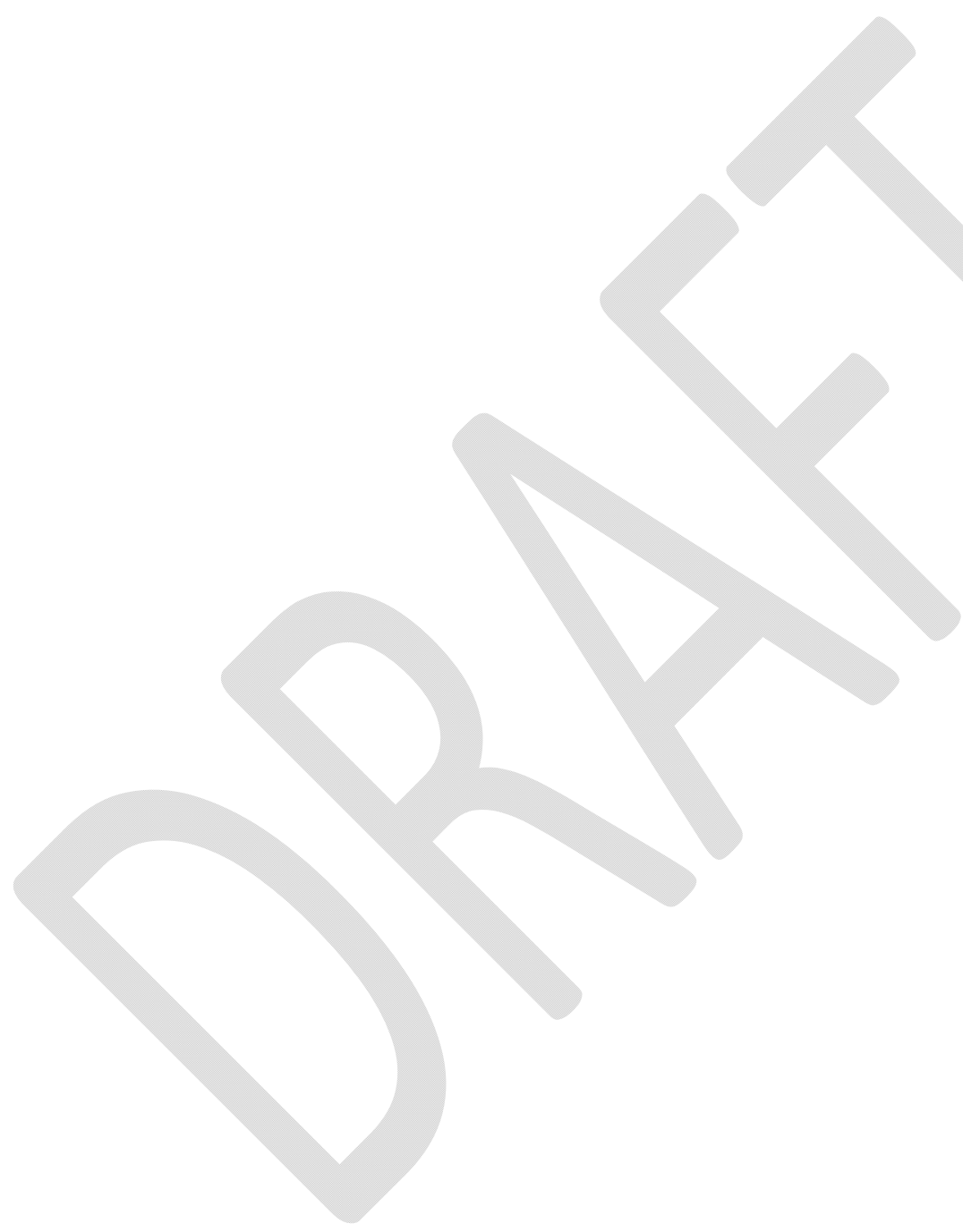


Figures and Tables

\begin{tabular}{|c|c|c|c|c|c|}
\hline Patient characteristics & $\begin{array}{c}\text { Caucasian } \\
(2891,88 \%)\end{array}$ & $\begin{array}{l}\text { Hispanic } \\
(190,6 \%)\end{array}$ & $\begin{array}{l}\text { Asian } \\
(145 \\
4 \%)\end{array}$ & $\begin{array}{c}\text { African } \\
\text { American } \\
(67,2 \%)\end{array}$ & $\mathbf{p}$ \\
\hline Age (mean $\pm \mathrm{SD})$, year & $68 \pm 10.6$ & $68 \pm 11.2$ & $68.7 \pm 11.4$ & $64.9 \pm 11.6$ & 0.09 \\
\hline $\begin{array}{l}\text { Sex, n }(\%) \\
\text { Male } \\
\text { Female }\end{array}$ & $\begin{array}{c}2336(80.80) \\
555(19.20)\end{array}$ & $\begin{array}{c}150 \\
(78.95) \\
40(21.05)\end{array}$ & $\begin{array}{c}110 \\
(75.86) \\
35 \\
(24.14)\end{array}$ & $\begin{array}{l}44(65.67) \\
23(34.33)\end{array}$ & 0.009 \\
\hline $\begin{array}{l}\mathrm{BMI}(\text { mean } \pm \mathrm{SD}), \\
\mathrm{kg} / \mathrm{m}^{2}\end{array}$ & $27.4 \pm 5.3$ & $28.4 \pm 5.5$ & $24.4 \pm 4.4$ & $28.5 \pm 6.4$ & $<0.001$ \\
\hline Smoking & $2165(74.89)$ & $\begin{array}{c}135 \\
(71.05)\end{array}$ & $\begin{array}{c}72 \\
(49.66)\end{array}$ & $49(73.17)$ & $<0.001$ \\
\hline $\begin{array}{l}\text { ASA score, n (\%) } \\
1-2 \\
3-4\end{array}$ & $\begin{array}{l}581(28.22) \\
1478(71.78)\end{array}$ & $\begin{array}{c}34(21.12) \\
127 \\
(78.88)\end{array}$ & $\begin{array}{c}50 \\
(38.46) \\
80 \\
(61.54) \\
\end{array}$ & $\begin{array}{l}10(17.54) \\
47(82.46)\end{array}$ & 0.003 \\
\hline $\begin{array}{l}\text { CCI, n (\%) } \\
0 \\
1 \\
\geq 2\end{array}$ & $\begin{array}{c}1337(49.63) \\
571(21.20) \\
786(29.18)\end{array}$ & $\begin{array}{l}98(52.97) \\
34(18.38) \\
53(18.65)\end{array}$ & $\begin{array}{c}66 \\
(58.53) \\
37 \\
(27.21) \\
33 \\
(24.26) \\
\end{array}$ & $\begin{array}{l}35(53.03) \\
13(19.70) \\
18(27.27)\end{array}$ & 0.57 \\
\hline $\begin{array}{l}\text { Time from diagnosis to } \\
\text { treatment (mean } \pm \mathrm{SD}) \text {, } \\
\text { days }\end{array}$ & $75.4 \pm 15.9$ & $85.5 \pm 92.8$ & $76.8 \pm 83.1$ & $81.8 \pm 64.7$ & $<0.001$ \\
\hline $\begin{array}{l}\text { Neoadjuvant } \\
\text { chemotherapy, n }(\%)\end{array}$ & $407(14.08)$ & $36(18.95)$ & $\begin{array}{c}25 \\
(17.24) \\
\end{array}$ & $10(14.93)$ & 0.23 \\
\hline $\begin{array}{l}\text { Clinical stage, n }(\%) \\
\leq \mathrm{T} 2, \mathrm{~N} 0 \\
\geq \mathrm{T} 3, \mathrm{~N} 0 \\
\mathrm{~N}+\end{array}$ & $\begin{array}{c}2495(86.30) \\
265(9.17) \\
131(4.53)\end{array}$ & $\begin{array}{c}147 \\
(77.37) \\
24(12.63) \\
19(10.00)\end{array}$ & $\begin{array}{c}116 \\
(80.00) \\
23 \\
(15.86) \\
6(4.14)\end{array}$ & $\begin{aligned} 58 & (86.57) \\
5 & (7.46) \\
4 & (5.97)\end{aligned}$ & 0.001 \\
\hline Pathological stage, n (\%) & & & & & \\
\hline
\end{tabular}




\begin{tabular}{|c|c|c|c|c|c|}
\hline $\begin{array}{l}\leq \mathrm{T} 2, \mathrm{~N} 0 \\
\geq \mathrm{T} 3, \mathrm{~N} 0 \\
\mathrm{~N}+\end{array}$ & $\begin{array}{c}1685(58.25) \\
578(19.99) \\
628(21.72)\end{array}$ & $\begin{array}{c}100 \\
(52.63) \\
40(21.05) \\
50(26.32)\end{array}$ & $\begin{array}{c}91 \\
(62.76) \\
30 \\
(20.69) \\
24 \\
(16.55)\end{array}$ & $\begin{array}{l}35(52.54) \\
15(22.39) \\
17(25.37)\end{array}$ & 0.40 \\
\hline Carcinoma in situ, $\mathrm{n}(\%)$ & $1609(55.66)$ & $98(51.58)$ & $\begin{array}{c}72 \\
(49.66)\end{array}$ & $32(47.76)$ & 0.21 \\
\hline $\begin{array}{l}\text { Lymphovascular } \\
\text { invasion, } \mathrm{n}(\%)\end{array}$ & $797(27.57)$ & $59(31.05)$ & $\begin{array}{c}39 \\
(26.90) \\
\end{array}$ & $20(29.85)$ & 0.73 \\
\hline Positive margins, $\mathrm{n}(\%)$ & $162(5.60)$ & $12(6.32)$ & $5(3.45)$ & $3(4.48)$ & 0.66 \\
\hline $\begin{array}{l}\text { Diversion, n (\%) } \\
\text { Orthotopic } \\
\text { Heterotopic }\end{array}$ & $\begin{array}{l}1659(57.38) \\
1232(42.62)\end{array}$ & $\begin{array}{c}116 \\
(61.05) \\
74(38.95)\end{array}$ & $\begin{array}{c}93 \\
(64.14) \\
52 \\
(35.86)\end{array}$ & $\begin{array}{l}36(53.73) \\
31(46.27)\end{array}$ & 0.28 \\
\hline $\begin{array}{l}\text { Associated variant } \\
\text { histology, n (\%) }\end{array}$ & $585(20.24)$ & $40(21.05)$ & $\begin{array}{c}24 \\
(16.55)\end{array}$ & $18(26.87)$ & 0.37 \\
\hline Transfusion & $1323(45.76)$ & $\begin{array}{c}100 \\
(52.63) \\
\end{array}$ & $\begin{array}{c}82 \\
(56.55)\end{array}$ & $37(55.22)$ & 0.01 \\
\hline
\end{tabular}

ASA American Society of Anesthesiologists; BMI: body mass index: CCI: Charlson comorbidity index; SD: standard deviation.

\begin{tabular}{|l|c|c|c|c|c|}
\hline \multicolumn{6}{|l|}{ Table 2. Perioperative complications and oncological outcomes stratified by race } \\
\hline Patient characteristics & Caucasian & Hispanic & Asian & $\begin{array}{l}\text { African } \\
\text { American }\end{array}$ & p \\
\hline 90-day complications, n & $534(18.47)$ & $50(26.32)$ & 49 & $14(20.90)$ & $<0.001$ \\
$(\%)$ & $214(7.40)$ & $28(14.74)$ & $(33.79)$ & $6(8.96)$ & \\
Low-grade & & 13 & & \\
High-grade & & $(8.97)$ & & \\
& & & & & \\
90-day complication & $173(5.98)$ & $9(4.74)$ & 19 & $3(4.48)$ & 0.004 \\
subgroups, n (\%) & $67(2.32)$ & $4(2.11)$ & $(13.10)$ & $1(1.49)$ & 0.97 \\
Cardiac & $558(19.30)$ & $45(23.68)$ & $3(2.07)$ & $17(25.37)$ & 0.46 \\
Pulmonary & $354(12.24)$ & $35(18.42)$ & 39 & $9(13.43)$ & 0.46 \\
GI & $143(4.95)$ & $10(5.26)$ & $(26.90)$ & $6(8.96)$ & 0.52 \\
GU & $508(17.57)$ & $43(22.63)$ & 13 & $19(28.36)$ & 0.31 \\
DVT & $96(3.32)$ & $3(1.58)$ & $(8.97)$ & $1(1.49)$ & 0.48 \\
Infection & $143(4.95)$ & $21(11.05)$ & $8(5.52)$ & $5(7.46)$ & $<0.001$ \\
Neurologic & $176(6.09)$ & $13(6.84)$ & 31 & $6(8.96)$ & 0.78 \\
Bleeding & $95(3.29)$ & $9(4.74)$ & $(21.38)$ & $5(7.46)$ & 0.2 \\
Surgical &
\end{tabular}




\begin{tabular}{|c|c|c|c|c|c|}
\hline $\begin{array}{l}\text { Wound } \\
\text { Other }\end{array}$ & $182(6.30)$ & $14(7.37)$ & $\begin{array}{c}4(2.76) \\
13 \\
(8.97) \\
9(6.21) \\
4(2.76) \\
17 \\
(11.72)\end{array}$ & $4(5.97)$ & 0.08 \\
\hline 90-day readmission, $\mathrm{n}(\%)$ & $312(10.97)$ & $36(18.95)$ & $\begin{array}{c}21 \\
(14.85)\end{array}$ & $12(17.91)$ & 0.001 \\
\hline Operative mortality & $45(1.56)$ & $4(2.11)$ & $2(1.38)$ & $0(0)$ & 0.55 \\
\hline $\begin{array}{l}\text { Recurrence, n (\%) } \\
\text { Local } \\
\text { Distant }\end{array}$ & $\begin{array}{c}189(6.54) \\
649(22.45)\end{array}$ & $\begin{array}{c}11(5.79) \\
39(20.53)\end{array}$ & $\begin{array}{c}11 \\
(7.59) \\
30 \\
(20.69) \\
\end{array}$ & $\begin{array}{c}2(2.98) \\
18(26.87)\end{array}$ & - \\
\hline $\begin{array}{l}\text { Overall survival (mean } \pm \\
\text { SD) } \\
\text { 3-year } \\
\text { 5-year }\end{array}$ & $\begin{array}{l}68 \pm 1 \% \\
60 \pm 1 \%\end{array}$ & $\begin{array}{l}70 \pm 3 \% \\
56 \pm 4 \%\end{array}$ & $\begin{array}{l}71 \pm 3 \% \\
55 \pm 5 \%\end{array}$ & $\begin{array}{l}64 \pm 6 \% \\
57 \pm 6 \%\end{array}$ & 0.90 \\
\hline 3-year RFS (mean \pm SD) & $70 \pm 1 \%$ & $71 \pm 3 \%$ & $69 \pm 5 \%$ & $68 \pm 5 \%$ & 0.97 \\
\hline
\end{tabular}

DVT: deep vein thrombosis; GI gastrointestinal; GU:genitourinary; RFS: recurrence-free survival; SD: standard deviation.

\begin{tabular}{|c|c|c|c|c|}
\hline \multirow{2}{*}{ Prognostic factors } & \multicolumn{2}{|c|}{ Survival } & \multicolumn{2}{|c|}{ Recurrence } \\
\hline & HR $(95 \%$ CI) & p & HR (95\% CI) & $\mathbf{p}$ \\
\hline $\begin{array}{l}\text { Race } \\
\text { Caucasian } \\
\text { Hispanic } \\
\text { Asian } \\
\text { African American }\end{array}$ & $\begin{array}{c}\text { Referent } \\
0.977(0.758-1.260) \\
0.985(0.742-1.307) \\
1.226(0.850-1.767)\end{array}$ & $\begin{array}{l}0.86 \\
0.91 \\
0.27 \\
\end{array}$ & $\begin{array}{c}\text { Referent } \\
0.845(0.613-1.167) \\
0.967(0.686-1.362) \\
0.976(0.601-1.586)\end{array}$ & $\begin{array}{l}0.31 \\
0.85 \\
0.92 \\
\end{array}$ \\
\hline $\begin{array}{l}\text { Decades } \\
1971-1979 \\
1980-1989 \\
1990-1999 \\
2000-2009 \\
2010-2017 \\
\end{array}$ & $\begin{array}{c}\text { Referent } \\
0.670(0.354-1.265) \\
0.750(0.395-1.425) \\
0.607(0.319-1.155) \\
0.455(0.236-0.878)\end{array}$ & $\begin{array}{l}0.22 \\
0.38 \\
0.13 \\
0.02\end{array}$ & $\begin{array}{c}\text { Referent } \\
1.235(0.390-3.908) \\
1.318(0.416-4.177) \\
1.291(0.409-4.080) \\
1.367(0.429-4.357) \\
\end{array}$ & $\begin{array}{l}0.72 \\
0.64 \\
0.66 \\
0.60 \\
\end{array}$ \\
\hline $\begin{array}{l}\text { Age } \\
\leq 65 \\
>65\end{array}$ & $\begin{array}{c}\text { Referent } \\
1.810(1.596-2.052)\end{array}$ & $<0.001$ & $\begin{array}{c}\text { Referent } \\
1.108(0.950-1.294)\end{array}$ & 0.19 \\
\hline Sex & & & & \\
\hline
\end{tabular}


Impact of race on outcomes and complictaions in bladder cancer

\begin{tabular}{|c|c|c|c|c|}
\hline $\begin{array}{l}\text { Male } \\
\text { Female }\end{array}$ & $\begin{array}{c}\text { Referent } \\
0.862(0.750-0.990)\end{array}$ & 0.03 & $\begin{array}{c}\text { Referent } \\
1.038(0.869-1.239) \\
\end{array}$ & 0.68 \\
\hline $\begin{array}{l}\text { Charlson } \\
\text { comorbidity index } \\
0 \\
\geq 1\end{array}$ & $\begin{array}{c}\text { Referent } \\
1.308(1.168-1.466)\end{array}$ & $<0.001$ & $\begin{array}{c}\text { Referent } \\
0.955(0.822-1.108)\end{array}$ & 0.54 \\
\hline $\begin{array}{l}\text { Pathologic lymph } \\
\text { node status } \\
\text { Negative } \\
\text { Positive } \\
\end{array}$ & $\begin{array}{c}\text { Referent } \\
1.559(1.234-1.969)\end{array}$ & $<0.001$ & $\begin{array}{c}\text { Referent } \\
1.703(1.323-2.191)\end{array}$ & $<0.001$ \\
\hline $\begin{array}{l}\text { Lymphovascular } \\
\text { invasion } \\
\text { Negative } \\
\text { Positive } \\
\end{array}$ & $\begin{array}{c}\text { Referent } \\
1.965(1.742-2.217)\end{array}$ & .001 & $\begin{array}{c}\text { Referent } \\
2.810(2.407-3.280)\end{array}$ & $<0.001$ \\
\hline $\begin{array}{l}\text { Urinary diversion } \\
\text { Orthotopic } \\
\text { Heterotopic }\end{array}$ & $\begin{array}{c}\text { Referent } \\
1.451(1.274-1.653)\end{array}$ & $<0.001$ & $\begin{array}{c}\text { Referent } \\
1.293(1.095-1.526)\end{array}$ & 0.002 \\
\hline $\begin{array}{l}\text { Neoadjuvant } \\
\text { chemotherapy } \\
\text { No } \\
\text { Yes }\end{array}$ & $\begin{array}{c}\text { Referent } \\
1.307(1.100-1.555)\end{array}$ & 0.002 & $\begin{array}{c}\text { Referent } \\
1.835(1.507-2.235)\end{array}$ & $<0.001$ \\
\hline $\begin{array}{l}\text { Adjuvant } \\
\text { chemotherapy } \\
\text { No } \\
\text { Yes }\end{array}$ & $\begin{array}{c}\text { Referent } \\
0.739(0.637-0.856)\end{array}$ & $<0.001$ & $\begin{array}{c}\text { Referent } \\
1.055(0.885-1.258)\end{array}$ & 0.55 \\
\hline
\end{tabular}

CI: confidence interval; HR: hazard ratio. 